MONITORAMENTO AMBIENTAL

\title{
ÁREAS DE RISCOS NA CIDADE DE EMBU DAS ARTES, SÃO PAULO - SP
}

\author{
Thays França Afonso - thaysafonso@ hotmail.com \\ Universidade Federal de Pelotas \\ Carolina Faccio Demarco - carol_demarco@ hotmail.com \\ Universidade Federal de Pelotas \\ Ana Luiza Bertani Dall’ Agnol - analuizabda@ gmail.com \\ Universidade Federal de Pelotas \\ Luis Eduardo Silveira da Mota Novaes - Luis.eduardo.novaes@ gmail.com \\ Universidade Federal de Pelotas \\ Robson Andreazza - robsonandreazza@yahoo.com.br \\ Universidade Federal de Pelotas
}

\section{Resumo}

Como toda a grande São Paulo, Embu das Artes também sofre com os problemas de enchentes e deslizamentos de terra, devido à existência de muitos morros e baixadas. Esses problemas se agravam devido à ocupação desordenada e irregular, o que resulta na formação de áreas de risco para a população. O presente trabalho pretende mostrar os tipos de áreas de riscos encontradas na cidade da Instância Turística de Embu das Artes no estado de São Paulo, através de visitas técnicas a campo no período do verão, onde ocorre o maior número de incidentes ambientais de movimentação de massa, em função das intensas chuvas na região. Verificou-se a existência de 42 áreas de riscos, sendo que a maioria está localizada em rochas do tipo Micaxistos e/ou Meta Arenitos, e que a movimentação de massa em 2015 comparada com o ano de 2010 ainda repete em cinco áreas. Conclui-se que na área de estudo há presença de movimentação de massa/solapamento/deslizamento/enchentes, e que os problemas mais graves foram identificados em áreas onde predominou a ocupação desordenada e irregular. 


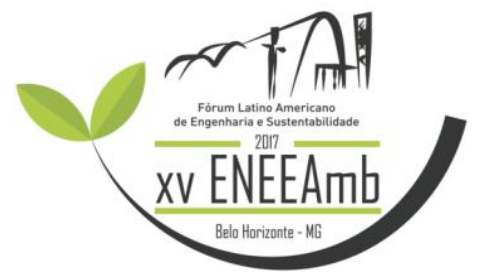

\section{Introdução/Objetivos}

A Estância Turística de Embu das Artes se encontra na Região Metropolitana do Estado de São Paulo - Brasil, o principal acesso ao município é pela Rodovia Régis Bittencourt (BR 116) quilômetros 279 e 282, estando a trinta minutos do centro de São Paulo. Os municípios limítrofes são Cotia, Taboão da Serra, São Paulo e Itapecerica da Serra. De acordo com os dados do IBGE a população estimada em 2016 é de 264448 habitantes ocupando uma área territorial de $70,398 \mathrm{~km}^{2}$. O município possui $59 \%$ de seu território em Área de Proteção aos Mananciais, fazendo parte da Reserva da Biosfera do Cinturão Verde da Cidade de São Paulo e, está inserido no Bioma Mata Atlântica. (EMBU DAS ARTES, 2009).

Como toda a grande São Paulo, Embu das Artes também sofre com os problemas de enchentes e deslizamentos de terra, devido à existência de muitos morros e baixadas. Essa condição do território, com o rio M'Boy Mirim, córregos e áreas verdes, associada à ocupação irregular, resulta na formação de áreas de risco para a população. No município de Embu, a Defesa Civil é instituída como COMDEC (Coordenadoria Municipal de Defesa Civil) atuando na assistência humanitária e socorro à população em caso de desastre (EMBU DAS ARTES, 2015).

Nesta cidade ocorrem escorregamentos que é definido como qualquer tipo de evento que envolva deslocamento de solos e/ou rochas caracterizando um deslizamento ou escoamento de solos e/ou rochas, independente de sua velocidade de ocorrência, abrangência geográfica ou de seu registro geológico (TAKAHASHI, 1998).

Fatores como: litologias, estruturas, condições geomorfológicas e condições hidrológicas locais influenciam na espessura dos solos, e estes fatores são exatamente os mesmos que caracterizam, juntamente com as condições climáticas locais, a evolução geomorfológica de uma região. O equilíbrio entre estes fatores tendem para superfícies completamente aplainadas, em consequência da erosão (incluindo escorregamentos) de áreas altas, consequente transporte e deposição da massa de detritos em áreas baixas (incluindo depósitos stone lines, depósitos coluviais e assoreamentos de drenagens) (RODRIGUEZ, 1998). 
Embora existam teorias aceitáveis sobre o comportamento mecânico dos solos em processo de escorregamentos, segundo Takahashi (1998), elas não traduzem a potencialidade e a previsibilidade de novas ocorrências em situações similares devido às heterogeneidades dos fatores condicionantes.

Dentre os fatores que condicionam os escorregamentos podemos citar as causas relacionadas às condições endógenas e exógenas. Entendem-se como processos exógenos aqueles cuja tendência é atuar sobre a paisagem geomorfológica, construindo superfícies niveladas por gradação ou sedimentação, ou atuar nos processos de degradação superficial da crosta terrestre promovendo o intemperísmo, a erosão e os escorregamentos (RODRIGUEZ, 1998).

Os principais fatores intrínsecos predisponentes à ocorrência dos escorregamentos, tais como litologia, estruturas, geomorfologia, hidrologia e clima, vegetação, associados à quantidade de carga imposta sobre o terreno devido à ocupação irregular ou inadequada em determinadas áreas, condicionam eventos de escorregamentos ou movimentação de massa.

De acordo com Rodriguez (1998) as áreas de potencialidade média ou alta possuem maior incidência de escorregamentos na Região Metropolitana de São Paulo. Áreas com menores potencialidades de ocorrência de escorregamentos encontram-se em terrenos sedimentares da Bacia de São Paulo, enquanto zonas com potencialidades mais elevadas se apresentam ao redor da bacia. As zonas com potencialidade alta são também representadas pelos grupos São Roque e Serra do Itaberaba, ocorrendo na região noroeste, e pelos domínios do Complexo Embu, principalmente na região sudoeste.

Nessas regiões são conhecidas áreas com riscos de escorregamentos, tais como nos municípios de Franco da Rocha, Francisco Morato, Caieiras e Cajamar, nos domínios dos grupos São Roque e Serra do Itaberaba; e Bairro de Campo Limpo, município de São Paulo, Itapecerica da Serra, Embu e Taboão da Serra, nos domínios do Complexo Embu.

Diante disso, o presente trabalho pretende mostrar os tipos de áreas de riscos encontradas na cidade da Instância Turística de Embu das Artes no estado de São Paulo. 


\section{Metodologia}

De acordo com Barros e Lehefeld (2000), a metodologia científica é o estudo na qual consiste em obter dados através do método a ser empregado na pesquisa, levando em conta todos os dados pertinentes ao estudo necessários para obtenção do conhecimento no caso a ser estudado.

A metodologia empregada nesta pesquisa envolveu procedimentos de documentações diretas e indiretas.

A documentação direta foi obtida mediante a realização de trabalhos de campo na cidade Estância Turística de Embu das Artes, São Paulo, e revisões bibliográficas pertinentes ao tema, sendo que a documentação indireta ficou restrita de dados em fontes secundárias, a partir do levantamento, localização, compilação de dados necessários ao desenvolvimento do trabalho.

O tipo de abordagem desta pesquisa deu-se de forma exploratória e descritiva, com vistas a avaliar, observar, registrar e analisar o ambiente que se delimita o tema proposto Geologia Urbana - Áreas de Riscos - Meio Ambiente, com fim único de se obter informações plausíveis a respeito do tema avaliado nessa pesquisa (BARROS e LEHEFELD, 2000).

O método de pesquisa descritivo ao qual ocorre a investigação do assunto em pauta se mostra presente nesse estudo de caso e que, de acordo com Cervo e Beviam (2000), consiste na pesquisa sobre um determinado nicho ecológico que abrange indivíduos, grupos, famílias dentro das suas comunidades, que possam revelar, e tornar possível o conhecer sobre esses membros e a situação a qual ele se insere.

Tendo feito o levantamento bibliográfico sobre os assuntos correlatos a Geologia ambiental da área urbana - Áreas de Riscos - Defesa Civil, do qual foi realizada com ajuda de ferramentas de pesquisa como internet (artigos científicos, dissertações e teses de mestrado ou doutorado), livros disponíveis em bibliotecas, partiu-se para a coleta de dados adotando como prática além da pesquisa documental, as visitas a campo, feita 
com os profissionais da Prefeitura Municipal da Estância Turística de Embu das Artes na Coordenadoria Municipal da Defesa Civil.

Nos meses de dezembro do ano de 2015 a janeiro do ano de 2016, foram realizadas as atividades conforme descrito na Tabela 1.

Tabela 1. Cronograma de Atividades no período de 12/2015 à 01/2016.

\begin{tabular}{c|c|c|c|c|c|c}
\hline SEMANA & $\mathbf{1}^{\mathbf{a}}$ & $\mathbf{2}^{\mathbf{a}}$ & $\mathbf{3}^{\mathbf{a}}$ & $\mathbf{4}^{\mathbf{a}}$ & $\mathbf{5}^{\mathbf{a}}$ & $\mathbf{6}^{\mathbf{a}}$ \\
SEMANA & SEMANA & SEMANA & SEMANA & SEMANA & SEMANA \\
\hline $\begin{array}{c}\text { Reconhecimento } \\
\text { das áreas de riscos }\end{array}$ & & & & & & \\
\hline $\begin{array}{c}\text { Leitura do } \\
\text { mapeamento das } \\
\text { áreas de riscos } \\
\text { (Antigo/Atual) }\end{array}$ & & & & & & \\
\hline $\begin{array}{c}\text { Confecção de } \\
\text { mapas }\end{array}$ & & & & & & \\
\hline $\begin{array}{c}\text { Revisão } \\
\text { bibliográfica }\end{array}$ & & & & & & \\
\hline $\begin{array}{c}\text { Acompanhamento } \\
\text { e vistorias de } \\
\text { emergências }\end{array}$ & & & & & & \\
\hline $\begin{array}{c}\text { Vistorias das áreas } \\
\text { de riscos contidas } \\
\text { no mapeamento }\end{array}$ & & & & & & \\
\hline Coleta de material & & & & & & \\
\hline $\begin{array}{c}\text { Registro de } \\
\text { Imagens }\end{array}$ & & & & & & \\
\hline $\begin{array}{c}\text { Sugestões de } \\
\text { melhorias }\end{array}$ & & & & & & \\
\hline $\begin{array}{c}\text { Entrega do } \\
\text { relatório }\end{array}$ & & & & & & \\
\hline \begin{tabular}{c} 
Encerramento \\
\hline
\end{tabular} & & & & & \\
\hline
\end{tabular}

\section{Resultados e Discussão}

Com o levantamento feito durante o período de pesquisas foi possível verificar a existência de 42 áreas de riscos, sendo que a maioria está localizada em rochas do tipo Micaxistos (Figura 2) e/ou Meta Arenitos (Figura 1), e que a movimentação de massa em 2015 (Tabela 2) comparada com o ano de 2010 ainda repete em cinco áreas. 


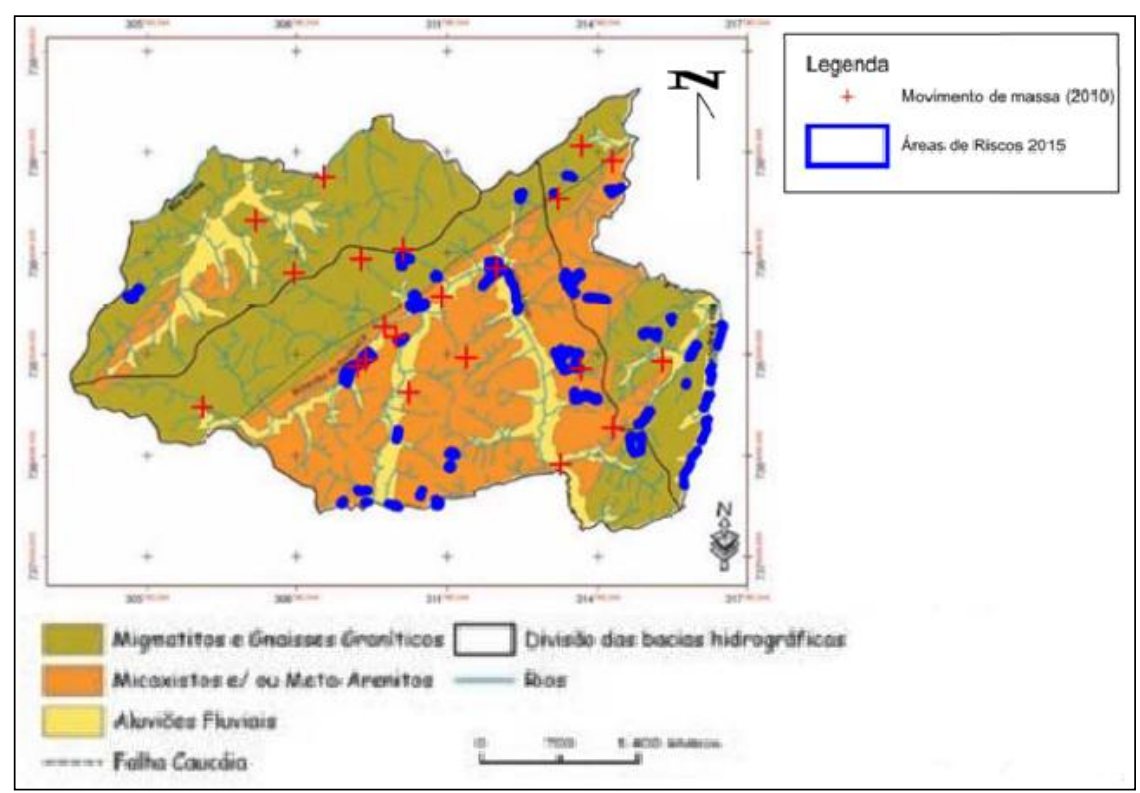

Figura 1: Mapa Geológico Embu das Artes com as áreas de riscos.

Fonte: Emplasa 2009 adaptado.

Tabela 2. Área de Riscos na Cidade de Embu das Artes - SP no ano de 2015.

\begin{tabular}{c|l}
$\begin{array}{c}\text { Área de } \\
\text { Risco }\end{array}$ & \multicolumn{1}{c}{ Endereço de Referência } \\
\hline 1 & Rua Torre de Chanceler \\
\hline 2 & Avenida Chico Mendes \\
\hline 3 & Estrada de Constantinopla \\
\hline 4 & Esquina das ruas Capri e Orleans \\
\hline 5 & Dois Palitos/Jardim da Luz \\
\hline 6 & Ruas Botucatu, Nonoai e João Guimarães Rosa \\
\hline 7 & Rua Minas Gerais \\
\hline 8 & Fundos da Rua Panorama \\
\hline 10 & Ruas Santos Dumont e Panorama \\
\hline 11 & Encostas das ruas Santana do Parnaíba e Vasco da Gama \\
\hline 12 & Encosta da Rua Bonfiglioli \\
\hline 13 & Campo João Marreta \\
\hline & Rua Duerê \\
\hline
\end{tabular}


Continuação

\begin{tabular}{|c|c|}
\hline 14 & Ísis Cristina (encosta e baixada) \\
\hline 15 & Rodoanel \\
\hline 16 & Entre as avenidas da Liberdade e Capivari \\
\hline 17 & Morro ao final da Avenida Capivari \\
\hline 18 & Entorno da Abba Motors \\
\hline 19 & Rua Marcelino Pinto Teixeira \\
\hline 20 & Galpão do Jardim Silvia \\
\hline 21 & Rua Lazar Segall \\
\hline 22 & Rua Rio G. do Norte e Vielas Rondônia e Montes Claros \\
\hline 23 & Entre as ruas Santa Catarina e Paraná \\
\hline 24 & Rua Jair Amaro do Amaral \\
\hline 25 & Entre a Rua Abraão e Estrada Prof. Candido Mota Filho \\
\hline 26 & $\begin{array}{l}\text { Encosta entre as ruas Ranulfo Lira e Luiz de Almeida } \\
\text { Carvalho }\end{array}$ \\
\hline 27 & Estrada Kaiko \\
\hline 28 & Rua Paiaguás \\
\hline 29 & Estrada Antonio Oliveira \\
\hline 30 & Entre a Estrada Maria Imaculadae Viela Robalo \\
\hline 31 & Parque Pinheiros \\
\hline 32 & Sítio Rima \\
\hline 33 & Avenida Hercílio Wustemberg \\
\hline 34 & Rua Jatobá \\
\hline 35 & Encosta entre as ruas Bananeiras e Cerejeiras \\
\hline 36 & Rua Santa Inês \\
\hline 37 & Rua Santa Rosa \\
\hline 38 & Rua Santa Gertrudes \\
\hline 39 & Rua Serra do Mar (Boqueirão) \\
\hline 40 & Entre as ruas Campo Grande e Maceió \\
\hline 41 & Avenida Dona Cesária Camargo de Oliveira \\
\hline 42 & Campinho na Estrada São Judas \\
\hline
\end{tabular}

As áreas de riscos que se repetem são as 4, 5, 9, 14, 18, destas observou-se que em muitos casos essas áreas estavam locadas sobre rochas bastante alteradas o que permitiu a formação de saprólitos (grego: saprós= podre; litos=rocha), condicionado a movimentação de massa e escorregamentos encontrados na região. 

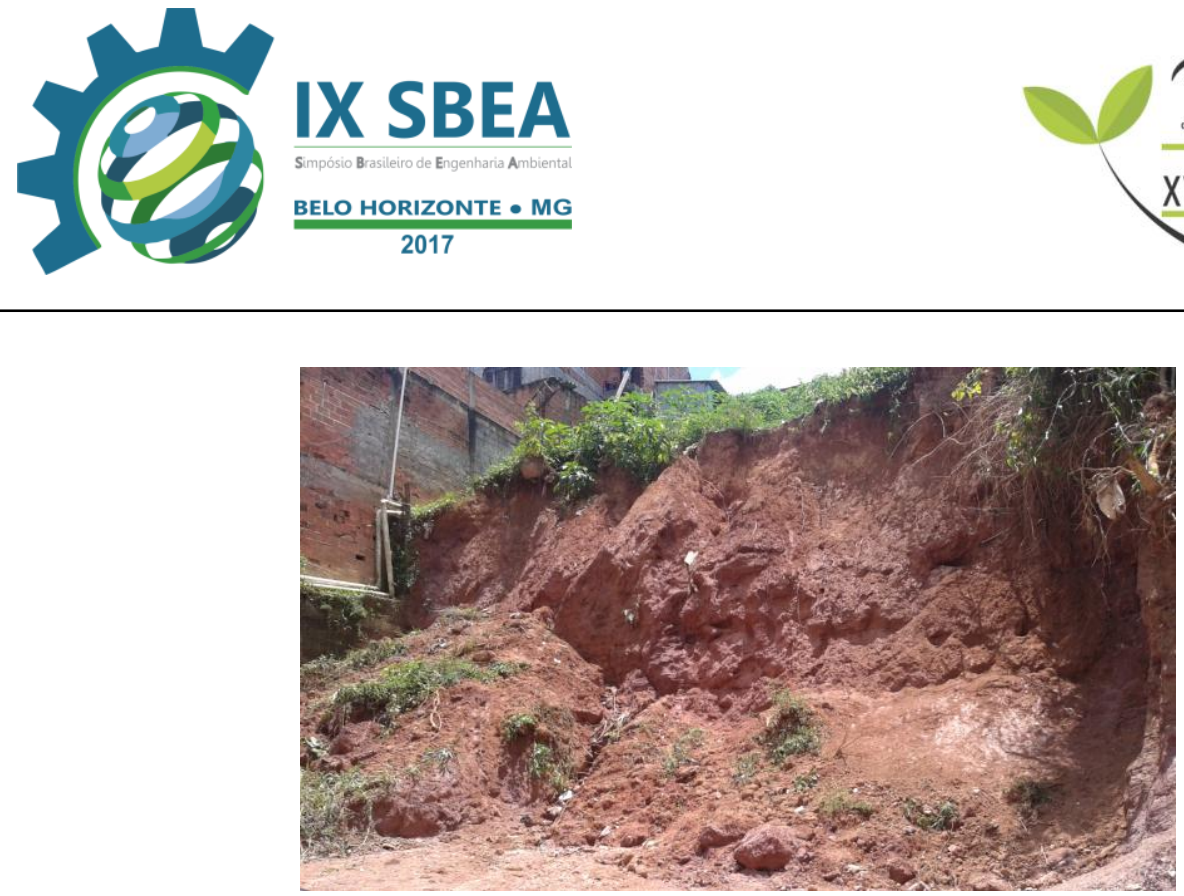

Figura 2: Micaxisto alterado formando saprólito.

As ocupações urbanas em áreas impróprias ocorrem com grande frequência na região, como o município é formado por morros e baixadas, e as construções em muitas áreas são precárias, acaba sendo suscetível a riscos de movimentação de massa (Figura 3) e alagamentos (Figura 4).
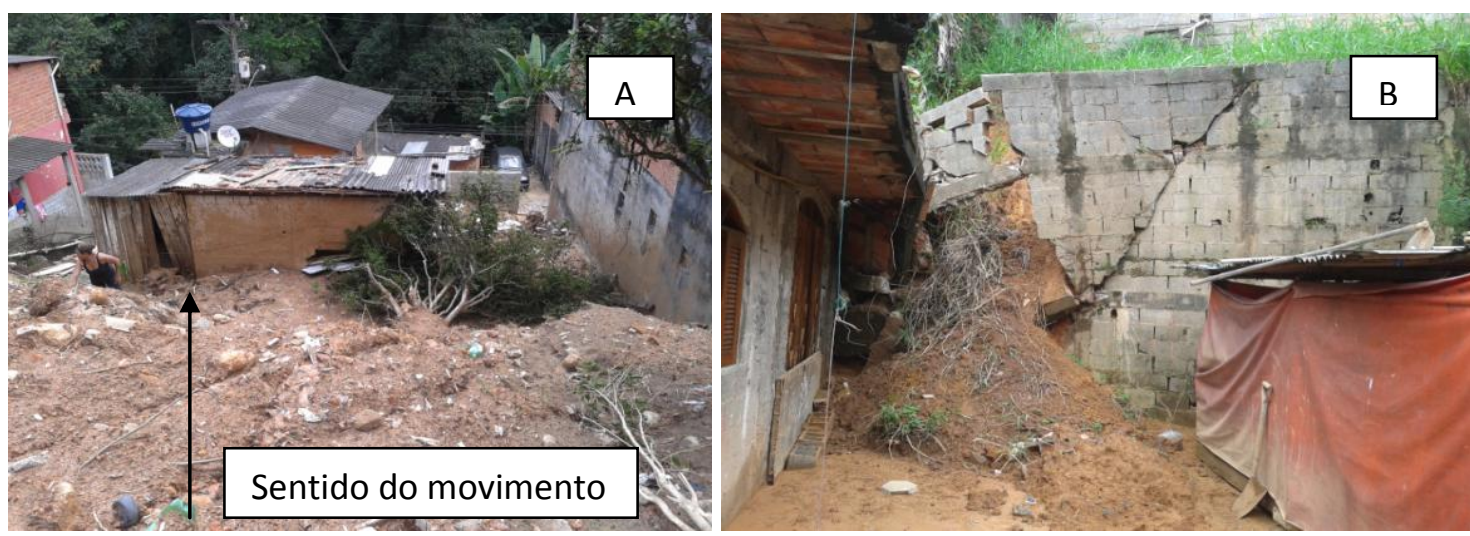

Figura 3: Movimentação de massa.

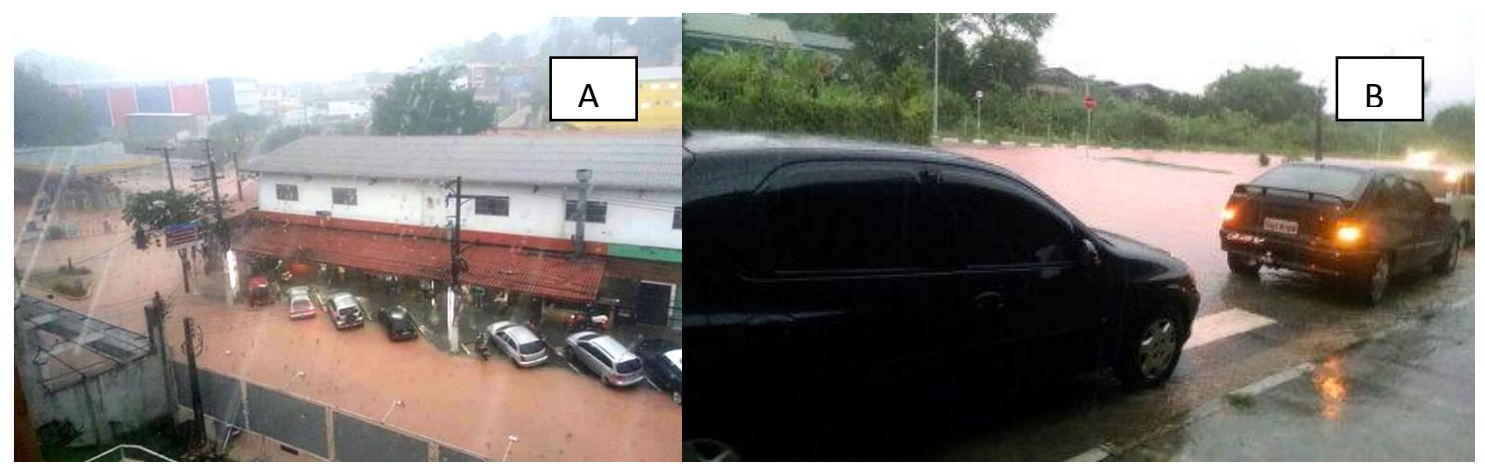

Figura 4: Alagamento em trecho da Av. Elias Yazbek em 12/12/2015. 

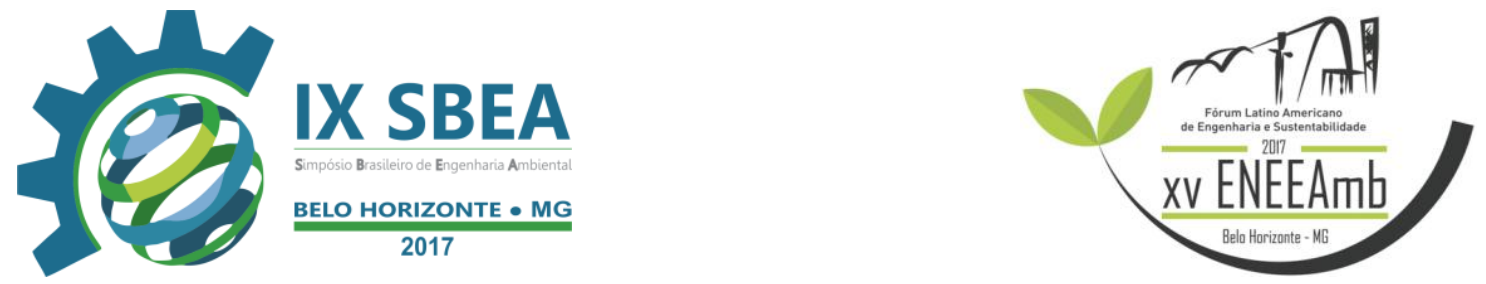

Devido às intensas chuvas que ocorrem no verão e falta de drenagem eficiente notam-se áreas de alagamentos e alguns casos de inundações. A lama é carreada para os corpos hídricos ocasionando assoreamento (Figura 5) e o fluxo da correnteza causa solapamento das margens dos córregos (Figura 6).

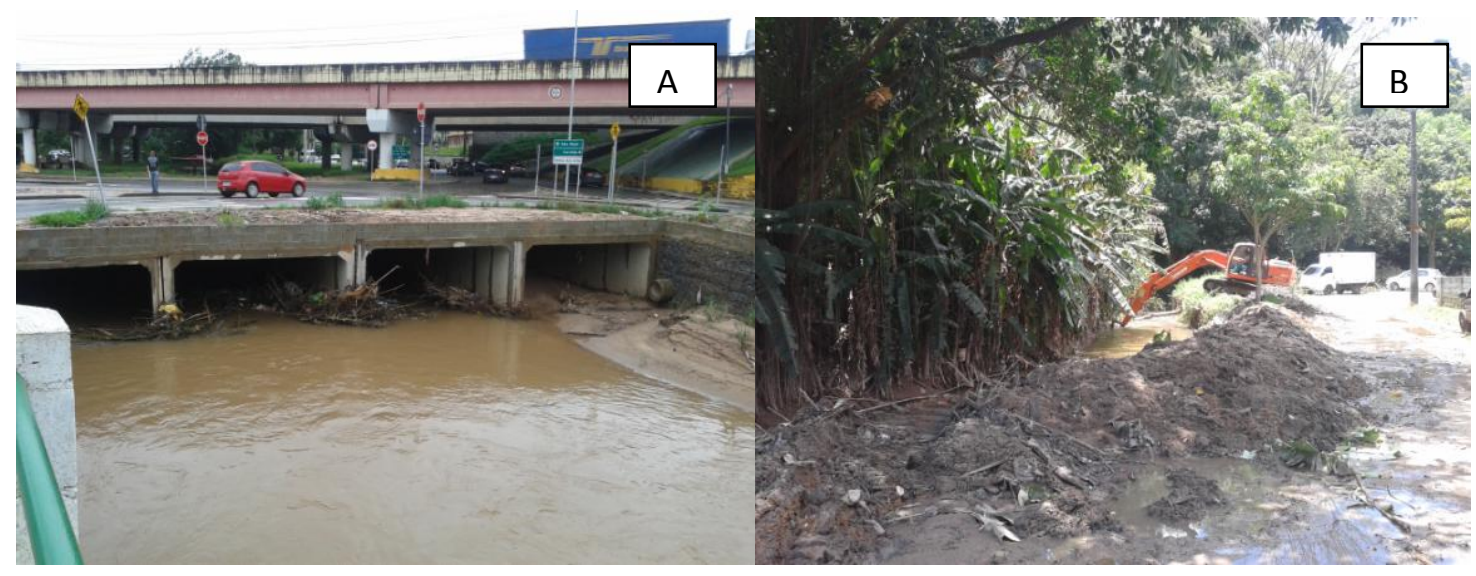

Figura 5: A - Assoreamento; B - Desassoreamento.

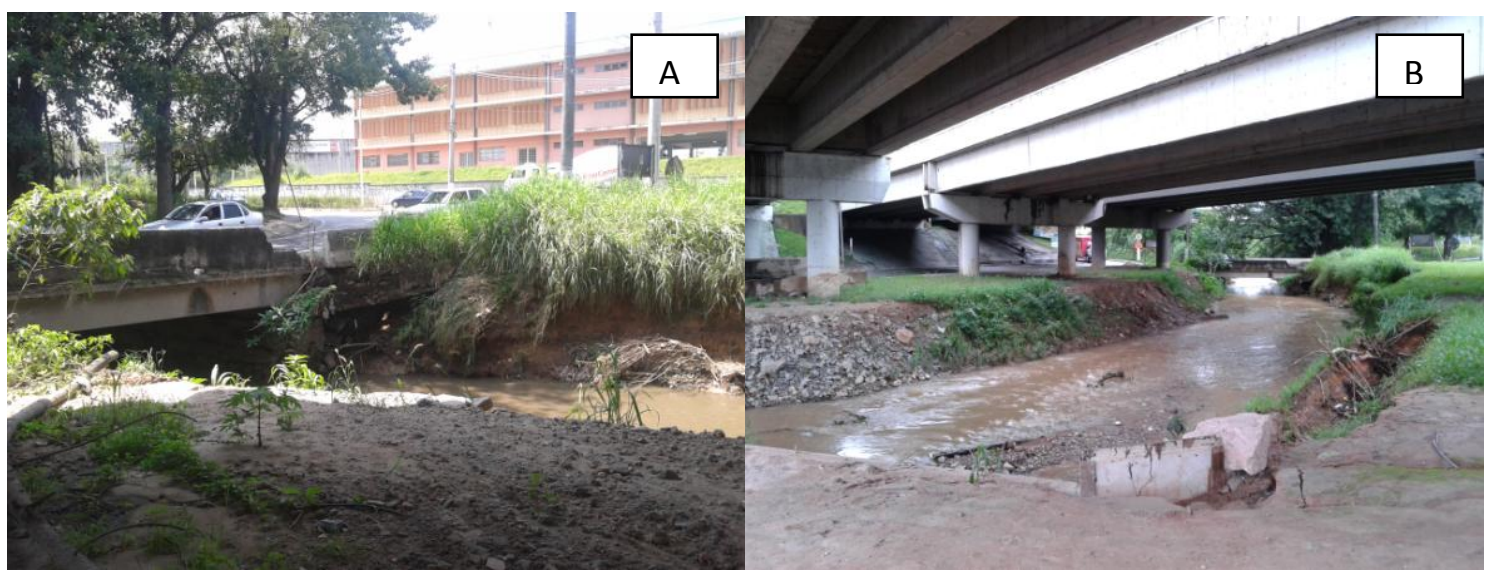

Figura 6: Solapamento da margem do rio.

\section{Conclusão}

Conclui-se que na área de estudo há presença de movimentação de massa/solapamento/deslizamento/enchentes. Percebeu-se que os problemas mais graves foram identificados em áreas onde predominou a ocupação desordenada e irregular e, a despeito da ação contínua da fiscalização, pessoas insistem em escavar encostas naturais/áreas públicas, desestabilizando-as e iniciam as obras das residências sem o tratamento do talude de corte, e o devido licenciamento assim como a análise de risco do local. 
De maneira geral, predomina nesses locais, a falta de infraestrutura básica para ocupação de encostas, tais como:

$\checkmark$ Saneamento básico e drenagem de águas superficiais para retirar águas servidas e pluviais das encostas, principal vilão e agente de risco geológico nessas áreas;

$\checkmark$ Pavimentação devida das ruas;

$\checkmark$ Tratamento do talude de corte com obra de contenção/impermeabilização previamente analisada por técnico habilitado e devidamente licenciada e com responsável técnico, realizada antes do início das obras do imóvel;

Sugere-se que haja uma melhoria na infraestrutura da cidade, principalmente relacionado à coleta de águas pluviais e servidas. Estas ações mitigariam em grandes dimensões os transtornos causados, por alagamentos, inundações deslizamentos.

Quanto à movimentação de massa pode-se empregar em taludes de cortes o capim Vetiver (vetiveria zizanioides), que é uma gramínea perene, que ocorre nos mais variados climas, sobretudo tropical e subtropical. Porte médio, chegando a até 1,50 $\mathrm{m}$ de altura, resistente a pragas, doenças, déficit hídrico, geadas e fogo. Possui crescimento ereto, formando touceiras e reproduz somente por mudas. Apresenta sistema de raízes densas e de alta resistência, atingindo $3 \mathrm{~m}$ de profundidade. As raízes apresentam sistema radicular agregante, formando um grampeamento natural estabilizante de encostas e taludes.

\section{Referências Bibliográficas}

BARROS, A. J. da S.; LEHEFELD, N. A. S. Fundamentos de metodologia científica. 2. ed. Ampliada. São Paulo: Pearson Education do Brasil. 2000.

CERVO, A. L.; BEVIAN, P. A. Metodologia científica. 5. ed. São Paulo: Prentice Hall. 2002.

EMPLASA. Empresa Paulista de Planejamento Metropolitano. Mapa Geológico Embu das Artes com as áreas de riscos. São Paulo. 2009. 
PREFEITURA Municipal da Estância Turística de Embu das Artes - Atlas Ambiental. 2009. São Paulo.

Municipal da Estância Turística de Embu das Artes - Defesa Civil/ Instituída como COMDEC (Coordenadoria Municipal de Defesa Civil). São Paulo. 2015.

RODRIGUEZ, S.K. 1998. Geologia Urbana da Região Metropolitana de São Paulo.

Tese de Doutoramento apresentada ao Instituto de Geociências da Universidade de São Paulo, 171p, mapas.

TAKAHASHI, T. 1998. Mechanics and countermeasures for the debris flow. Apostila do curso Debris flow oferecido pela Escola Politécnica da Universidade de São Paulo em julho de 1998. 103p. 